\title{
Hadewijch. Entre el misticismo y la pasión, el superyó
}

\author{
Hadewijch | Bruno Dumont | 2009 \\ Mariana Gómez \\ Universidad Nacional de Córdoba
}

Recibido 28 de septiembre de 2018; aceptado: 17 de octubre 2018

\begin{abstract}
Resumen
En el presente artículo se trabaja a partir de la película Hadewijch de Bruno Dumont (2009), la cual está inspirada en una joven a la cual su dolor de existir la empuja a una pasión fanática hasta las últimas consecuencias. El trabajo radica en la articulación de dicha película con el fenómeno del fanatismo, en una de sus versiones, el misticismo. Sostiene la premisa que hablar de fanatismo implica la cuestión del cuerpo y parte de tres puntos: el masoquismo, lo femenino y el superyó. Se pregunta por el superyó en toda pasión fanática, y la relación del mismo con el goce femenino. De este modo se aborda al misticismo desde el masoquismo originario, pensándolo en relación a lo femenino del superyó que empuja a gozar desmesuradamente. A partir de un recorrido por dichas categorías teóricas, se busca responder qué lleva a Hadewijch a tal fanatismo místico y hasta dónde puede llegar esta mujer por un amor fanático hacia el otro.
\end{abstract}

Palabras clave: lo femenino | masoquismo | goce femenino | fanatismo | Superyó femenino | cuerpo

\section{Hadewijch. Between mysticism and passion, the superego}

\begin{abstract}
This article is based on the film Hadewijch by Bruno Dumont (2009), which is inspired by a young woman whose pain of being pushes her to a fanatical passion until the last consequences. This work lies in the articulation of this film with the fanaticism phenomenon, in one of its versions, mysticism. It maintains the premise that speaking of fanaticism implies the question of the body and parts of three points: masochism, the feminine and the superego. The question is asked about the superego in all fanatical passions, and its relationship with feminine jouissance. In this way, mysticism is approached from the original masochism, thinking it in relation to the feminine of the superego that pushes to jouissance disproportionately. From a journey through these theoretical categories, we seek to answer what leads Hadewijch to such mystical fanaticism and how far this woman can go by a fanatical love for the other.
\end{abstract}

Key words: the feminine | masochism | feminine jouissance | fanaticism | feminine superego | body

En el siglo XII existió una mujer que vivió en la ciudad de Amberes. Pertenecía a una comunidad de mujeres católicas que se sometían a la vida religiosa que, sin constituirse en un convento, se dedicaban a la contemplación extrema y a realizar obras de caridad entre pobres y enfermos. Esta mujer, llamada Hadewijch (Julie Sokolowski), se dio a conocer y perduró en la historia gracias a su obra escrita, basada en sus propias experiencias místicas. Experiencias y reflexiones que nos llevan a ubicarla como una apasionada de la caridad y del amor, una verdadera mística.

Hadewijch ha sido la inspiración del cineasta Bruno Dumont para su película del mismo nombre, quien nos muestra a una Hadewijch del siglo XXI. Una joven de hoy pero que no difiere demasiado de la anterior, en ese dolor de existir que la empujaba a una pasión fanática hasta las últimas consecuencias.

Voy a tomar tres puntos de partida para trabajar la película y el tratamiento que ésta hace del fenómeno del fanatismo y una de las versiones de este, el misticismo. ${ }^{1}$ Estos tres disparadores son: el masoquismo, lo femenino y el superyó. Condiciones del fanatismo místico, que encontraremos desplegados a lo largo de las páginas de Aún, Seminario 20 (1972-73 [1995]) de Lacan.

Aún, en francés, se escribe encore y su pronunciación consuena con en corps, "en cuerpo". Como vemos, el nombre de este seminario ya nos pone en la pista de lo que Lacan nos enseña respecto del cuerpo y del anudamiento entre los tres aspectos mencionados.

* margo@ffyh.unc.edu.ar 
¿Cómo un sujeto podría defender con tenacidad sus creencias si no es a partir de la ceguera de lo exterior de sí mismo? Hablar de fanatismos nos lleva entonces, sin dudas, a la cuestión del cuerpo. ¿Es que es posible pensar a un fanático si no es en relación a las pasiones, al pathos? Porque, se sostiene la pasión con el cuerpo y se soporta el sufrimiento que ésta despierta, también con el cuerpo.

Pero además, toda pasión fanática estará siempre atravesada por un superyó desmedido, en su anudamiento con el goce femenino, que se sostendrá en un masoquismo originario, en el decir de Freud. Lo femenino del superyó implica ese modo de gozar desmesurado, que empuja al más y más, al aún y aún más. El misticismo sería una de sus caras. Fenómeno sobre el que nos enseña Lacan en su Seminario 20 (1972-73 [1995]).

En la época en la que Lacan dictaba este seminario había recibido en su consulta a una religiosa con un modo de gozar bastante parecido al de Hadewijch. Ella había sido paciente de Lacan a lo largo de cuatro años. Se llamaba Marie de la Trinité. Era una mujer que había sido atendida por unos veinte psiquiatras y ninguno de ellos pudo ayudarla a salir de la inmensa angustia que soportaba. Solo Lacan pudo conducirla a encontrar una salida, como ella misma lo dice en sus escritos. Marie de la Trinité llevaba un diario al Igual que Hadewijch de Amberes.

Esta religiosa tenía un afán y era el de cumplir con todos los deberes y con la mayor de las dedicaciones. $\mathrm{Y}$ es este empuje el que la va llevando a severas crisis de angustia y de depresión extremas (Lázaro, 2013). Había una palabra que marcaba su vida y era "perfección".

Los psiquiatras que la veían consideraban que lo que a ella le sucedía respondía a sus votos de castidad, pero Lacan señala ese error y va a decir que el padecimiento tenía que ver con la obediencia. Su cuestión era la obediencia. Se trataba de una obediencia ciega. Ella deseaba obedecer más allá de lo que se le pedía.

El tratamiento de Lacan apuntó, así, a deconsistir esto. No me detendré en este punto, pero tal vez sea interesante señalar que las reflexiones sobre las místicas que aparecen en su Seminario 20 (1972-73 [1995]) fueron inspiradas en esta paciente, Marie.

El personaje que nos presenta Bruno Dumont padece de manera similar. Se trata de una joven para quien el vacío respecto del Otro la deja en un lugar de absoluta soledad. Dumont nos la muestra hija de una madre melancólica y de un padre que mira para otro lado. Y entonces, ella buscará desesperadamente a un Otro. Que también la expulsará, como la directora del convento donde ella va por refugio y consuelo.

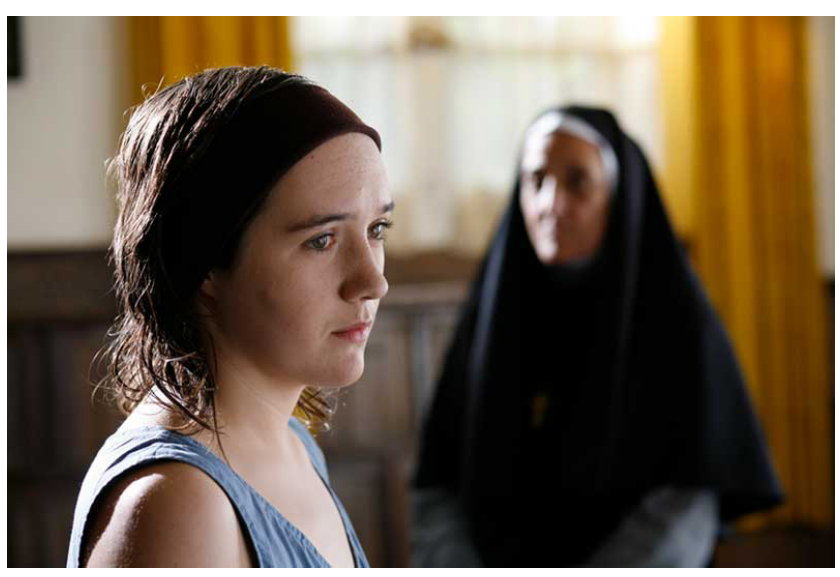

Es en medio de esa desolación que la joven se encuentra con otros dos tan solos como ella. Entonces, de rezarle al Dios del catolicismo pasará al de la religión musulmana. El Uno del fundamentalismo la alojará subjetivamente ocupando la función de un padre, para ella carente.

Sin embargo, nada para Hadewijch es suficiente y frente al vacío y al dolor subjetivo, solo le quedará el automartirio, el misticismo, el fanatismo religioso.

Así, la frase de su amigo le tocará el cuerpo, cuando refiriéndose a Alá, le dice: "nosotros somos sus soldados y también sus mártires”.

Es el anudamiento entre lo femenino y el superyó en su versión masoquista, que nos va a permitir localizar, como más arriba anticipaba, lo que Bruno Dumont nos da a ver con esta película.

\section{La crueldad del Superyó}

El concepto de Superyó implica para el Psicoanálisis una cuestión paradójica y ésta reside en que el sujeto, gracias al Superyó, ingresa en su vida una serie de valores, normas éticas y morales pero, al mismo tiempo, se apega a algo que no colabora con su bienestar y que lo hace sufrir. Por eso, Freud (1913-14 [1996]) lo incluye en la misma línea que el masoquismo primordial y la pulsión de muerte.

Así el Superyó, por un lado, es aquello que instala al sujeto en la cultura y se presenta como articulado a la prohibición del incesto, en representación del padre ligado a la castración. Es el heredero del Complejo de Edipo y por eso Freud nos dice que el Superyó conserva el carácter del padre y que en cierta medida toma prestada su fuerza. Incluso, cuanto más rápido se haya producido 
la represión en el sujeto, tanto más riguroso devendrá el imperio del Superyó, como conciencia moral y como sentimiento inconsciente de culpa, sobre el Yo (Freud, 1913-14 [1996]).

Sin embargo, si bien Freud no abandonará esta idea del Superyó ligado a la socialización, en El Yo y el Elloaunque presentándolo como equivalente al ideal del Yolo ubicará ligado a algo más. Veremos, así, cómo la cuestión del sentimiento de culpa será el pivote para pensar las dos clases de pulsiones (Freud, 1924 [1996]).

En El Yo y el Ello, Freud (1924 [1996]) nos enseña que el Yo se forma desde identificaciones que toman el relevo de investiduras del Ello, resignadas. Estas identificaciones se comportan como una instancia particular dentro del Yo y se contraponen a éste como Superyó.

Así como el niño obedece a sus progenitores, el Yo se somete al imperativo del Superyó. Es decir, el Superyó desciende también de las primeras investiduras de objeto del Ello y, por lo tanto, previamente al Complejo de Edipo.

De esta manera, el Superyó es también reencarnación de anteriores formaciones yoicas, que han dejado su sedimento en el Ello. Por eso, mantiene duradera afinidad con éste y puede subrogarlo frente al Yo. Se sumerge profundamente en el Ello, por lo que está más distanciado de la conciencia que el Yo, y esto Freud lo asocia directamente a la reacción terapéutica negativa.

Sostiene que en estas personas prevalece la necesidad de estar enfermos. Así, nos dice, se trata de un sentimiento de culpa que halla su satisfacción en la enfermedad y en el no querer renunciar a su castigo del padecer. Este sentimiento de culpa es mudo. El enfermo no se siente culpable, sino enfermo.

El ejemplo paradigmático lo encontramos en algunas formas de la neurosis obsesiva, donde los reproches de la conciencia moral, son absolutamente martirizadores. Esto sucede porque, en la obsesión, una regresión a la organización pregenital posibilita que los impulsos de amor se muden en impulsos de agresión hacia el objeto. Así, la pulsión de destrucción queda liberada y quiere aniquilar al objeto amado. Pero, el Yo no acepta esto y se defiende con formaciones reactivas, de manera que estas tendencias permanecen en el Ello.

De este modo, el Superyó se comporta como si el Yo fuera el responsable de éstas. Así, el Yo debe defenderse en vano, por un lado, de las insinuaciones del Ello agresivo y por el otro, de los reproches del Superyó castigador. El resultado, un automartirio interminable.

Esto puede llevar a grandes malestares, aunque, en oposición a lo que ocurre en la melancolía, Freud sostiene que el neurótico obsesivo no llega a darse muerte, es como inmune al suicidio, inclusive está más protegido contra este acto que en la histeria. Vemos cómo es la conservación del objeto lo que garantiza la seguridad del Yo.

Pero en la melancolía advertimos que el Superyó se dirige, de otra manera, con furia y sadismo sobre el Yo. De acuerdo con la concepción del sadismo, el componente destructivo se ha depositado en el Yo, éste se siente odiado y perseguido por el Superyó, en vez de amado, y lo que en este caso gobierna es, por lo tanto, pura pulsión de muerte que, a menudo, logra efectivamente empujar al Yo hacia la misma muerte.

Pero, ¿por qué en la melancolía el Superyó puede convertirse en un cultivo para las pulsiones de muerte? Esto se debe a que, desde el punto de vista de la limitación de las pulsiones, el Ello es totalmente amoral, el Yo se empeña por ser moral y el Superyó es hipermoral, y por esta razón puede ser tan cruel como sólo puede serlo el Ello. Mientras el sujeto más limita su agresión hacia fuera, tanto más severo se torna el ideal del Yo contra el Yo.

\section{Superyó pulsional, gozar hasta la muerte}

Vemos, entonces, que el Superyó no sólo introduce al sujeto en la cultura de una manera benévola, vía la palabra paterna. Hay también otra vertiente que, lejos de producirle bienestar, lo sumerge en el sufrimiento del síntoma y del masoquismo. En estas dos vertientes, la primera, se da como heredera del complejo de Edipo, mientras que la segunda por la identificación inicial, ocurrida cuando el Yo era todavía endeble. Esta última conservará a lo largo de la vida su carácter de origen. Es lo que recuerda la endeblez y dependencia en las que se encontró en el pasado y mantiene su imperio sobre el Yo maduro. Así, el Yo se somete al imperativo categórico de su Superyó.

De esta manera, nos encontramos frente a un círculo vicioso en donde la instancia que obliga a la renuncia, alimenta a la vez a la pulsión y donde se puede gozar de la propia renuncia. En definitiva, el Superyó no es más que un disfraz del Ello.

De allí que en El Problema económico del masoquismo, al plantear Freud (1923 [1996]) la existencia de la mezcla de pulsiones, atribuya la peligrosidad que reside en el Superyó a que éste desciende de la pulsión de muerte. Pero como, por otra parte, tiene valor de un compo- 
nente erótico, ni aún la autodestrucción del sujeto puede producirse sin satisfacción libidinosa. Es lo que ocurre con el masoquista que, para provocar el castigo, se ve obligado a hacer cosas inapropiadas, a trabajar en contra de su propio beneficio.

Esto es porque la reversión del sadismo hacia la persona propia ocurre a raíz de la sofocación cultural de las pulsiones. Esa parte relegada de la pulsión de destrucción sale a la luz como masoquismo del Yo donde la destrucción que retorna del mundo exterior es acogida por el Superyó, aumentando, así, su sadismo hacia el Yo. Un interesante ejemplo de esta situación lo encontramos también en el personaje principal de la película "El Cisne Negro" de Darren Aronofsky (2011), una bailarina que sacrifica, al extremo, su cuerpo en obediencia al mandato materno de ser la mejor. Lo que en Hadewijch empuja como religión, en Nina Sayers, la protagonista, lo hace en el nombre de la danza.

Freud (1996 [1923]) reconoce, entonces, tres formas de masoquismo: el masoquismo erógeno, el femenino y el moral.

En el primero, condición y fundamento de las otras dos, el dolor aparece como condición de la excitación sexual; el segundo aparece como expresión de la naturaleza femenina, y el tercero como norma de la conducta de vida. En este último no hay zona erógena porque lo que está erogeneizado es la propia conciencia. El sadismo del Superyó y el masoquismo del Yo se complementan uno con otro y se aúnan provocando las mismas consecuencias.

Es decir, que cuanto más renuncia la pulsión, más se satisface y más culpable se siente el sujeto. Esto lo lleva a Freud (1996 [1923]) a plantear que no es la conciencia moral la que impone la renuncia, sino que es ésta la que instala la conciencia moral.

Esta cuestión también será trabajada en El malestar en la cultura (2009 [1929]) donde dirá que la necesidad de castigo es una exteriorización pulsional del Yo que ha devenido masoquista bajo el imperio del Superyó sádico, empleando un fragmento de la pulsión de destrucción preexistente en él en una ligazón erótica.

El Superyó, dijimos, entonces, se presenta en dos vertientes, la de la ley socializadora, pero también la de la ley insensata. Lacan, tomando la referencia freudiana, también lo trabajará.

En el Seminario 1, Los escritos técnicos de Freud (Lacan, 1953-54), ubica al Superyó sobre todo en el plano de lo simbólico, pero también dirá, con Freud, que no sólo es la ley socializadora, sino también la ley insensata. Es la ley del significante cuya significación desconocemos. Es, nos dice, la evidencia de un significante único que, por estar sólo, es insensato.

\section{Superyó, ¿̨femenino?}

Ahora bien, Freud (2009 [1931]) consideraba que el Superyó en las mujeres nunca se volvía tan implacable como en los hombres. Sin embargo, podemos decir que contrariamente a esta formulación, el superyó femenino puede ser tan tiránico e incluso más feroz que para el hombre. Para Miller (2003), el superyó no es otra cosa que una máscara del goce femenino. Y nos dice, "no hay más seres del deber que las mujeres" (Miller, en Durand, 2008, p. 21).

Antígona es un ejemplo paradigmático. Es una gran obediente, cumple con la voluntad de quien manda. Y quien manda para ella, su amo, es el Superyó. Para ella no mandan las leyes del Estado.

Lacan (1959-60 [1997]) en su Seminario 7, nos dice que ella lleva hasta el límite la realización de su deseo. $\mathrm{Su}$ hermano es condenado a muerte por traición y por eso se le niega sepultura. Entonces, desafía la ley, el ordenamiento jurídico, y le da sepultura a su hermano, aun sabiendo de las consecuencias de esto. Y este acto la lleva a su propia muerte. Su obediencia al amo superyoico la termina empujando a su ejecución.

Hay otras mujeres a las que Lacan se refiere para entender el concepto del Superyó femenino y su empuje al masoquismo. Mujeres a quienes su mandato superyoico las lleva a perderlo todo o, incluso, a su propia muerte.

Otro ejemplo es Medea. Una mujer que en su vida amorosa estuvo dispuesta a todo. Medea amaba a Jasón locamente. Ella había sacrificado todo por él. Había traicionado a su propio padre, a su país, a su familia. Estaba siempre de su lado, consentía sin límites a todos sus pedidos. Él le había prometido hacerla su esposa, jurándole que le sería siempre fiel.

Conviven durante 10 años y tienen dos hijos. Hasta que un día él le anuncia que va a casarse con otra. Y Medea empieza a odiar todo lo de él, también a sus propios hijos, a quienes terminará matando para vengarse. Le quita lo que él más quería. Dice: "mi dolor se ha calmado si ya no puedes reír”. Sacrifica lo más precioso que ella tenía, para lastimarlo a él.

Ahora, si bien el superyó pulsional se relaciona con lo femenino, a partir del sin límites que caracteriza a ambos, esto no implica una equivalencia. Se trata de diferentes 
formas de satisfacción. En efecto, una mujer puede articularse al falo o a un más allá de éste y ese allá del falo implicará al goce propiamente femenino, ilimitado, sin medida (Lacan, 1992 [1972-73]).

Sin embargo, este goce propiamente femenino, no incluye necesariamente al Superyó femenino, en tanto este último hunde sus raíces en la pulsión de muerte. Recordemos que el superyó mantiene una afinidad con el Ello. Su origen se da en el interior del Yo, cuando una parte del mismo se vuelve contra sí, volcando contra sí una agresividad que estaba destinada a otro. Freud nos dice que es "el cultivo puro de la pulsión de muerte". Es decir, el goce superyoico es solidario de la pulsión de muerte y puede llevar a una mujer al estrago. El otro, el femenino, es un goce vivificante, siempre y cuando logre ser soportado (Salamone, 2015).

Vemos entonces que en el personaje de la película, Hadewijch, hay una demanda infinita de amor. Le demanda a Dios, a su Dios, que le hable, que la ame. Se lo demanda infinitamente y como no obtiene respuesta, se ofrece, de manera cada vez más obediente, para conseguir lo que la empuja. Se somete a sacrificios, soporta el frio, el hambre. Y esa obediencia termina siendo lo peor para ella. Se convierte es una verdadera obediente de sí misma.

Entonces, Hadewijch se comporta respecto de su Dios como, tal vez, podría también posicionarse cualquier mujer no religiosa respecto de un hombre.

Una mujer dispuesta a todo, dispuesta a perderlo todo, su dinero, su dignidad, su salud, con tal obtener del amado una respuesta. Se trata de un superyó mortífero que la empuja a lo peor. Como Antígona, como Medea.

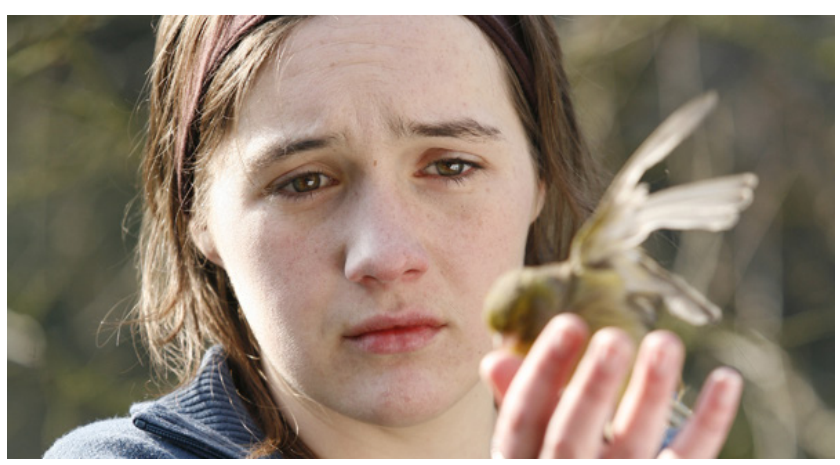

Una mujer comandada por un superyó implacable y obediente, y Dumont nos muestra cómo eso la lleva a la mayor de las devastaciones. Hadewijch se expone al peligro, pone en riesgo su cuerpo y finalmente, cuando ya no le queda nada, intenta el suicidio.

Bruno Dumont nos enseña con esta película hasta qué punto una mujer puede llegar por su amor loco y fanático por el otro.

A su vez, este film nos muestra muy bien lo que formuló Lacan: que podrá ser por un amor loco, podrá ser por celos, por el sentimiento de obediencia a la propia ley, a la ley de Dios, por las razones que sea, que un sujeto del lado femenino, puede llegar a sufrir infinitamente cuando se anudan goce femenino, superyó y masoquismo.

\section{Referencias}

Álvarez Villanueva, M. (2016). Teresa de Jesús y el goce femenino como principio general del goce. En El Psicoanálisis. Revista de la Escuela Lacaniana de Psicoanálisis, 28/2016.

Castro, E. (2016). Una mística en análisis con Lacan. En El Psicoanálisis. Revista de la Escuela Lacaniana de Psicoanálisis, $28 / 2016$.

Durand, I. (2008). El superyó, femenino. Las afinidades entre el superyó y el goce femenino. Buenos Aires: Tres Haches.

Freud, S. (1914 [1996]). Introducción del narcisismo. En Obras Completas. Volumen XIV. Buenos Aires: Amorrortu editores.

Freud, S. (1913 [1994]). Totem y Tabú. En Obras Completas. Volumen XIII. Buenos Aires: Amorrortu editores.

Freud, S. (1924 [1996]). El yo y el ello. En Obras Completas. Volumen XIX. Buenos Aires: Amorrortu editores.

Freud, S. (1924 [1996]). El problema económico del masoquismo. En Obras Completas. Buenos Aires: Amorrortu editores.

Freud, S. (1930 [2009]). El Malestar en la cultura. En Obras Completas. Volumen XXI. Buenos Aires: Amorrortu editores.

Freud, S. (1931 [2009]). Sobre la sexualidad femenina. En Obras Completas. Volumen XXI. Buenos Aires: Amorrortu editores.

Lacan, J. (1953-54 [1995]). Los escritos técnicos de Freud. En El Seminario. Libro 1,. Buenos Aires: Paidós.

Lacan, J. (1955-56 [1995]). El Yo en la teoría de Freud y en la técnica psicoanalítica. En El Seminario. Libro 2. Buenos Aires: Paidós.

Lacan, J. (1959-60 [1997]). La ética del psicoanálisis. En El Seminario. Libro 7. Buenos Aires: Paidós.

Lacan, J. (1972-73 [1992]). Aún. En El Seminario. Libro 20. Buenos Aires: Paidós.

Lázaro, C. (2013). Un problema de obediencia: Construcción del caso de Marie de la Trinité. En Lacaniana No 14. Buenos Aires: Grama. 
Laurent, E. (1999). Posiciones femeninas del ser. Buenos Aires: Tres Haches.

Miller, J.A. (1994). Recorrido de Lacan. Ocho conferencias. Buenos Aires: Manantial.

Miller (2003). Marie de la Trinite. En Revista Quarto, Revista de la ECF. Bélgica.

Salamone, L. D. (2015). Diferencias entre el goce femenino y el superyoico. En Virtulia\#30. Buenos Aires: EOL.

1 El misticismo, en general, designa un modo de experiencia en el cual se llega al grado máximo de unión del "alma humana” a lo Sagrado durante la existencia terrenal. Se da en las religiones monoteístas como en algunas politeístas y en religiones no teístas, como el budismo, donde se identifica con un grado máximo de perfección y conocimiento. Existen además otras vertientes que integran al concepto, pero que no desarrollaremos, aquí considerando los alcances de este trabajo. 